\title{
An integrated comparative physiology and molecular approach pinpoints mediators of breath-hold capacity in dolphins
}

Ashley M. Blawas ${ }^{1}$, Kathryn E. Ware ${ }^{2}$, Emma Schmaltz ${ }^{1}$, Larry Zheng ${ }^{1}$, Jake Spruance ${ }^{2}$, Austin

5 S. Allen ${ }^{1}$, Nicole West ${ }^{3}$, Nicolas Devos ${ }^{4}$, David L. Corcoran ${ }^{4}$, Douglas P. Nowacek ${ }^{1,5}$, William

${ }^{1}$ Nicholas School of the Environment, Duke University Marine Laboratory, Beaufort, NC, 28516, USA.

${ }^{2}$ Department of Medicine, Duke University Medical Center, Durham, NC, 27710, USA.

${ }^{3}$ Dolphin Quest, Oahu, 5000 Kahala Ave, Honolulu, HI, 96816, USA.

${ }^{4}$ Duke Center for Genomic and Computational Biology, Duke University, Durham, NC, 27708, USA.

${ }^{5}$ Pratt School of Engineering, Duke University, Durham, NC, 27708, USA.

${ }^{6}$ Department of Orthopaedic Surgery, Duke University Medical Center, Durham, NC, 27710, 21 USA.

${ }^{7}$ Duke University Medical Center, Duke Cancer Institute, Durham, NC, 27710, USA.

${ }^{8}$ Global Diving Research, Inc., Ottawa, ON, K2J 5E8, Canada.

${ }^{9}$ Research Department, Fundación Oceanogràfic de la Comunitat Valenciana, Gran Viá Marqués del Turia 19, 46005 Valencia, Spain.

Address correspondence to: jason.somarelli@duke.edu; andreas.fahlman@duke.edu

Keywords: ischemic stress tolerance; cetaceans; diving physiology; oceans and human health 


\section{Abstract}

34 Ischemic events, such as ischemic heart disease and ischemic stroke, are the number one cause of

35 death globally. Ischemia prevents blood, carrying essential nutrients and oxygen, from reaching

36 tissues and organ systems, leading to cell and tissue death, and eventual organ failure. While

37 humans are relatively intolerant to these ischemic events, other species, such as marine

38 mammals, have evolved remarkable tolerance to chronic ischemia/reperfusion during diving.

39 Here we capitalized on the unique adaptations of bottlenose dolphins (Tursiops truncatus) as a

40 comparative model of ischemic stress and hypoxia tolerance to identify molecular features

41 associated with breath-holding. Using RNA-Seq we observed time-dependent upregulation of the

42 arachidonate 5-lipoxygenase (ALOX5) gene during breath-holding. Consistent with the RNA-

43 Seq data, we also observed increased ALOX5 enzymatic activity in the serum of dolphins

44 undergoing breath holds. ALOX5 has previously been shown to be activated during hypoxia in

45 rodent models, and its metabolites, leukotrienes, induce vasoconstriction. The upregulation of

46 ALOX5 occurred within the estimated aerobic dive limit of the species, suggesting that ALOX5

47 enzymatic activity may promote tolerance to ischemic stress through sustained vasoconstriction

48 in dolphins during diving. These observations pinpoint a potential molecular mechanism by

49 which dolphins, and perhaps other marine mammals, have adapted to the prolonged breath-holds

50 associated with diving. 


\section{Introduction}

53 Ischemic stress and hypoxia are associated with negative clinical outcomes in humans.

54 Maintenance of homeostatic function in mammalian tissues is directly dependent on a continuous

55 supply of oxygenated blood. Interruption of this blood supply, known as ischemia, results in

56 reduction in local oxygenation compared to normal physiologic levels, or hypoxia, and can lead

57 to inflammation and cell/tissue death (Bona et al., 1999; Choi, 1996; Eltzschig and Carmeliet,

58 2011; Gottlieb and Engler, 1999; Murdoch et al., 2005). Ischemia is the causative factor in

59 multiple clinical settings, and ischemic heart disease is the number one cause of death globally,

60 accounting for over 9 million deaths each year (Nowbar et al., 2019; World Health Organization,

$612018)$

62

63 Marine mammals have evolved tolerance to ischemic stress. While humans have little tolerance

64 for ischemic stress and hypoxia, a number of species have evolved unique physiologies that

65 allow them to seemingly thrive despite regular tissue-level ischemia and low-oxygen

66 environments. One group of animals that undergo repeated daily ischemic events is marine

67 mammals. During a dive, a marine mammal experiences a suite of cardiovascular changes that

68 aid in reducing aerobic metabolism (Irving et al., 1941; Scholander, 1940). As part of this

69 response, both heart rate $\left(f_{\mathrm{H}}\right)$ and stroke volume decrease, resulting in reduced cardiac output

70 (Fahlman et al., 2020b, 2019b). Increased peripheral resistance, through selective

71 vasoconstriction, helps assure that mean arterial blood pressure is maintained, at least in studies

72 on forced diving in seals (Blix et al., 1976; Zapol et al., 1979). Ultimately, this response

73 conserves oxygen in the blood and lungs for oxygen-sensitive tissues like the brain and the heart,

74 while the skeletal muscles rely on endogenous myoglobin-bound oxygen for aerobic metabolism 


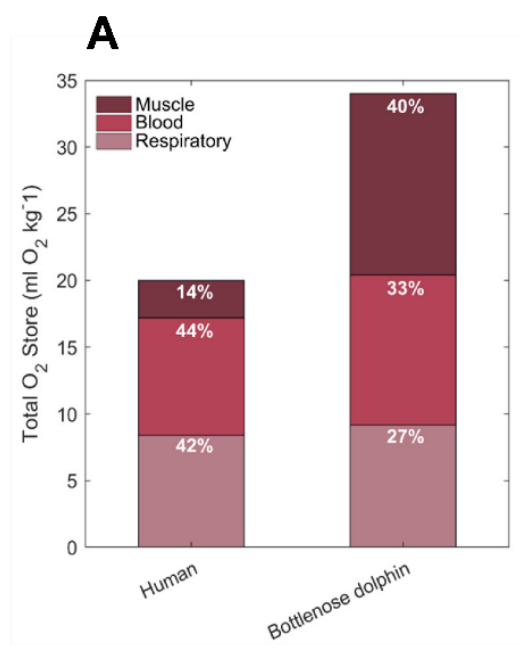

B

\begin{tabular}{lll}
\hline $\begin{array}{c}\text { Average dive } \\
\text { duration (min) }\end{array}$ & $0.5-0.67$ & 0.6 \\
\hline
\end{tabular}

\begin{tabular}{ccc}
\hline $\begin{array}{c}\text { Max dive } \\
\text { duration (min) }\end{array}$ & 11.6 & 13 \\
\hline CADL (min) & - & 6.5
\end{tabular}

Figure 1. Dolphins as a model of ischemia. A. Dolphins and other cetaceans have increased oxygen stores that are reapportioned compared to humans. Oxygen store data were reported in Ponganis et al., 2011 (human) and Kooyman and Ponganis, 2018 (dolphin). B. The enhanced oxygen stores and diving capacity of dolphins makes them a unique model to study ischemic stress tolerance. Dive data and calculated aerobic dive limit (cADL) were reported by AIDA and Foster and Sheel, 2005 (human) and Fahlman et al., 2018 (dolphin).

75 (Davis and Kanatous, 1999; Fahlman et al., 2009). While these responses to submersion in water are largely conserved across all vertebrates, many of the physiological adaptations that support

77 diving are exaggerated in marine mammals compared to other taxa (Kooyman and Ponganis,

78 1998; Panneton, 2013) (Figure 1). For example, maintenance of

79 increased peripheral resistance does not appear to occur in human breath-hold divers, as mean

80 arterial blood pressure increases with dive duration (Breskovic et al., 2011; Gooden, 1994;

81 Taboni et al., 2019). These physiological differences highlight the tremendous potential to study

82 marine mammals as model organisms for the investigation of adaptations to ischemic and

83 hypoxic stress tolerance, and the cardiorespiratory plasticity that helps prevent hypertension

84 (Blawas et al., 2021; Fahlman et al., 2019b, 2020b). 
Marine mammals have evolved molecular adaptations to ischemic stress tolerance. Increasing

87 attention has been paid to the defenses marine mammals possess against the oxidant by-products and inflammation associated with ischemic, hypoxia, and reperfusion at the molecular level

89 (Allen and Vázquez-Medina, 2019; Hindle, 2020; Zhu et al., 2018). Using phylogenetic and

90 evolutionary convergence approaches, several gene families have been identified to contribute to

91 the increased ischemic stress tolerance of marine mammals, including hypoxia-inducible factor 1

92 (HIF-1) (Bi et al., 2015; Johnson et al., 2005, 2004), genes relating to the glutathione system and

93 peroxiredoxins (Bagchi et al., 2018; Tift et al., 2014; Yim et al., 2014; Zhou et al., 2018), and

94 several genes linked to oxygen storage, particularly hemoglobin and myoglobin (Mirceta et al.,

95 2013; Nery et al., 2013; Tian et al., 2017, 2016). Yet, few studies have examined differential

96 gene expression in marine mammals under conditions of ischemia and hypoxia (i.e. diving

97 conditions).

98 Here, we investigate the dynamic molecular changes that occur during an apnea in

99 bottlenose dolphins using genomic analysis of peripheral blood mononuclear cells (PBMCs) and

100 serum sampled at regular intervals during breath-holds. We couple these analyses with

101 previously-published $f_{\mathrm{H}}$ measurements from the same dolphins to understand how the timing of

102 molecular changes relates to the physiologic dive response (Blawas et al., 2021; Fahlman et al.,

$1032019 b, 2020 b)$. Our integrated analyses pinpoint a gene regulatory network centered around the

104 arachidonate 5-lipoxygenase (ALOX5) gene and its downstream metabolites, leukotrienes, as

105 differentially activated during breath-holding. This activation of ALOX5 is consistent with

106 cardiovascular control through reduction in $f_{\mathrm{H}}$ and peripheral vasoconstriction to efficiently

107 manage $\mathrm{O}_{2}$ use during diving. Based on our collective results we propose a model in which the 
108 ALOX5 pathway is upregulated during extended breath-holds as a mechanism to sustain

109 vasoconstriction and maintain oxygen stores for critical organs while diving.

\section{Materials and Methods}

112 Data collection and animal information. Four adult male bottlenose dolphins (Tursiops

113 truncatus) housed at Dolphin Quest Oahu (Honolulu, HI, USA) with an average ( \pm S.D.) age of

$11422.8 \pm 9.9$ years $($ range $=11-35$ years $)$ and body mass of $198.1 \pm 42.9 \mathrm{~kg}($ range $=147.0-251.7$

$115 \mathrm{~kg}$, Table 1) participated in this study. All data were collected under voluntary participation and

116 the animals could end a trial at any time. Routine veterinary assessments include venous blood

117 sampling, and the dolphins that participated in this study had previously been desensitized to the

118 blood sampling protocol. The study protocols were accepted by Dolphin Quest and the Animal

119 Care and Welfare Committee at the Oceanogràfic (OCE-17-16, amendments OCE-29-18 and

120 OCE-3-19i).

Table 1. Animal ID, age (years), body mass (kg), and included analyses for all dolphins in the study.

\begin{tabular}{|l|c|c|c|c|}
\hline Animal ID & $\begin{array}{c}\text { Age } \\
\text { (years) }\end{array}$ & $\begin{array}{c}\text { Body Mass } \\
\mathbf{( k g )}\end{array}$ & $\begin{array}{c}\text { RNA- } \\
\text { Seq }\end{array}$ & $\begin{array}{c}\text { Lipoxygenase } \\
\text { assay }\end{array}$ \\
\hline $6 \mathrm{JK} 5$ & 24 & 200.9 & $\mathrm{x}$ & $\mathrm{x}$ \\
\hline 9FL3 & 35 & 251.7 & $\mathrm{x}$ & \\
\hline 9ON6 & 21 & 192.8 & $\mathrm{x}$ & $\mathrm{x}$ \\
\hline $83 \mathrm{H} 1$ & 11 & 147.0 & & $\mathrm{x}$ \\
\hline Mean \pm S.D. & $22.8 \pm 9.9$ & $198.1 \pm 42.9$ & & \\
\hline
\end{tabular}

122 Experimental trials. Serum was isolated from whole blood samples at baseline, 3 minutes, and 4

$1231 / 2-5$ minutes of breath-holding on fasted dolphins at Dolphin Quest, Oahu, March 2018 and

124 May 2019. All trials were performed in the morning, when the animals were fasted with at least 
12512 hours having passed since the last meal on the previous day to minimize the potential

126 confounding effect of nutritional state. To ensure that the samples were collected during resting

127 behavior each breath-hold was proceeded by 2 minutes of rest or slow swimming at the surface.

128 A trial was initiated when the dolphin rolled into dorsal recumbency with its blowhole

129 submerged and continued for approximately 5 minutes. The breath-hold ended when the animal

130 rolled into ventral recumbency and took a breath. Prior to this study the animals had previously

131 participated in breath-hold experiments of durations up to 5 minutes (Fahlman et al., 2019a,

132 2020b).

134 Blood collection and processing. Whole blood was collected from tail flukes at baseline (0-30

135 seconds into the breath-hold) and during breath-holding for 3 minutes and $4 \frac{1}{2}$ (2018) or 5

136 (2019) minutes while the animal was in dorsal recumbency with its blowhole submerged (Figure

137 2A). Blood was collected into PAXgene tubes and RNA-Seq was performed subsequent to

138 shipping, red blood cell lysis, RNA extraction (Figure 2A). All samples were shipped the same

139 day via overnight courier to Duke University for downstream processing. For RNA extraction,

140 tubes were equilibrated to room temperature for 2 hours to achieve complete lysis of blood cells.

141 Subsequently, tubes were centrifuged at 4,000 x g for 10 minutes. Pellets were resuspended in 4

$142 \mathrm{~mL}$ of RNase-free water and RNA was extracted according to the PAXgene Blood RNA kit

143 (PreAnalytiX \#762164). Prior to library prep, RNA quality was evaluated on a Bioanalyzer 2100

144 (Agilent). Stranded mRNA-seq libraries were prepared using the Nugen Universal Plus mRNA-

145 seq Library preparation kit with Globin AnyDeplete (Tecan \#9147-A01). Libraires were

146 sequenced at $150 \mathrm{bp}$ paired-end on one lane of an Illumina NovaSeq 6000 instrument S-Prime

147 flow cell. Library preparation and sequencing was performed in conjunction with the Duke 
148 University Sequencing and Genomic Technologies Shared Resource. Samples collected in 2018

149 were used to conduct RNA-Seq analysis and samples collected in 2019 were used for the

150 lipoxygenase assays.

152 RNA-Seq data analysis. RNA-seq data was processed using the TrimGalore toolkit (Krueger,

153 2020) which employs Cutadapt (Martin, 2011) to trim low-quality bases and Illumina sequencing

154 adapters from the 3' end of the reads. Only reads that were 20 nt or longer after trimming were

155 kept for further analysis. Reads were mapped to the turTrulv92 version of the dolphin genome

156 and transcriptome (Kersey et al., 2012) using the STAR RNA-seq alignment tool (Dobin et al.,

157 2013). Reads were kept for subsequent analysis if they mapped to a single genomic location.

158 Gene counts were compiled using the HTSeq tool (Anders et al., 2015). Only genes that had at

159 least 10 reads in any given library were used in subsequent analysis. Normalization and

160 differential expression across the time points were carried out using the DESeq2 (Love et al.,

161 2014) Bioconductor (Huber et al., 2015) package with the R statistical programming

162 environment(R Core Team, 2020). The false discovery rate was calculated to control for

163 multiple hypothesis testing. To identify relevant molecular features of dolphin breath-holding we

164 first analyzed the RNA-Seq data from all individuals at baseline using gene set enrichment

165 analysis (GSEA) (Mootha et al., 2003; Subramanian et al., 2005). GSEA is a standard pathway

166 analysis tool that calculates enrichment scores for annotated pathways based on the rank order of

167 genes present in the data for each pathway. Pathways with genes that are more up- or down-

168 regulated are more likely to be enriched in a data set than pathways whose genes are randomly

169 distributed throughout the data. Pathway enrichments in dolphin PBMCs at baseline, with genes 
170 ranked on total expression value, were compared with human whole blood pathway enrichments

171 from the Genotype-Tissue Expression (GTEx) project.

172

173 Construction of gene regulatory networks. Gene expression networks were created using

174 GeneMANIA (Franz et al., 2018), implemented within the Cytoscape platform (Shannon et al.,

175 2003). For time-dependent gene network construction all nodes with 0 or 1 connection were

176 trimmed out of the networks. Two additional non-coding RNA genes were eliminated (RF00016

177 and RF00026). To quantify network connectivity, all genes in the network were individually

178 ranked by the following network parameters: degree, clustering coefficient, closeness,

179 betweenness, neighborhood connectivity, and stress. These rankings were summed to generate a

180 sum rank score for each gene. Pathway enrichments were performed in STRING using the

181 trimmed network of 123 genes. Human whole blood transcriptomics data used for the analyses

182 described in this manuscript were obtained from the Genotype-Tissue Expression (GTEx)

183 Program Portal (https://gtexportal.org/home/) accessed on 9/20/2020.

185 Lipoxygenase assays. Briefly, $5 \mathrm{ml}$ of blood was collected directly into BD Vacutainer ${ }^{\circledR} \mathrm{SST}^{\mathrm{TM}}$

186 Tubes (SST) using a $21 \mathrm{~g}, 3 / 4$ in. winged infusion set with a BD Vacutainer adapter and holder.

187 Tubes were gently inverted 5 times to activate clotting reagent and allowed to clot at room

188 temperature for 30 minutes in an upright position. Tubes were centrifuged at 1,500 x $\mathrm{g}$ for 15

189 minutes to separate serum fractions, and serum was transferred to $15 \mathrm{ml}$ conical tubes, frozen on

190 dry ice, and shipped to Duke University for downstream analyses. Sera were stored at $-80^{\circ} \mathrm{C}$

191 until use. Lipoxygenase activity was quantified from $1 \mu \mathrm{g}$ of total protein using a Fluorometric

192 Lipoxygenase Activity Assay Kit (BioVision Inc; cat. \#K978). 


\section{Results}

194 RNA-Seq from dolphins at baseline pinpoints enriched gene regulatory networks. All samples

195 produced between 30 and 40 million reads, with no time-dependent changes in read counts

196 across samples (Supplementary Figure 1A). Principle components analysis and hierarchical

197 clustering of all samples (three individual dolphins $\mathrm{x}$ three time points) revealed both individual-

198 and within-individual time-dependent grouping of the data (Supplementary Figure 1B, C).

199 GSEA identified multiple pathways enriched in dolphin PBMCs at baseline when ranked by total

200 expression, including hedgehog signaling and several pathways relevant to blood cell

201 metabolism, including heme metabolism, coagulation, IL6/JAK/STAT3 activation, apical

202 junctions, and allograft rejection (Figure 2B, C). GSEA also identified enrichment of pathways

203 related to apical junctions, interferon alpha response, estrogen response, complement activity,

204 and heme metabolism in RNA-Seq data from GTEx human whole blood transcriptomes (Figure

205 2D). Comparison of dolphin baseline RNA-Seq data ranked by total expression with the top 100

206 and 500 most highly-expressed genes in human whole blood showed significant enrichment

207 (FDR $<0.0001)$ (Figure 2E). Together these analyses suggest that significant overlap exists in

208 mRNA expression at both the gene-level and pathway-level between dolphin and human blood.

210 Breath-holding induces upregulation of multiple regulatory pathways. We next reasoned that

211 patterns of step-wise increases in mRNA expression may pinpoint molecular responses to breath-

212 holding common across individuals. We constructed gene regulatory networks for 136 genes

213 with step-wise increases in mRNA expression from baseline to 3 minutes and again from 3

214 minutes to $4 \frac{1}{2}$ minutes (Figure 3A). We performed network analysis to identify genes that are

215 upregulated and have the most network interactions. To do this we analyzed the time-dependent 
216 gene regulatory network for the following parameters: degree, clustering coefficient, closeness,

217 betweenness, neighborhood connectivity, and stress. We then plotted the sum rank score of these

218 network parameters with gene expression for each gene in the network. These analyses

219 pinpointed arachidonate 5-lipoxygenase (ALOX5) as among the most connected genes with a

220 time-dependent increase in expression (Figure 3B, C). Additional genes, including EPX,

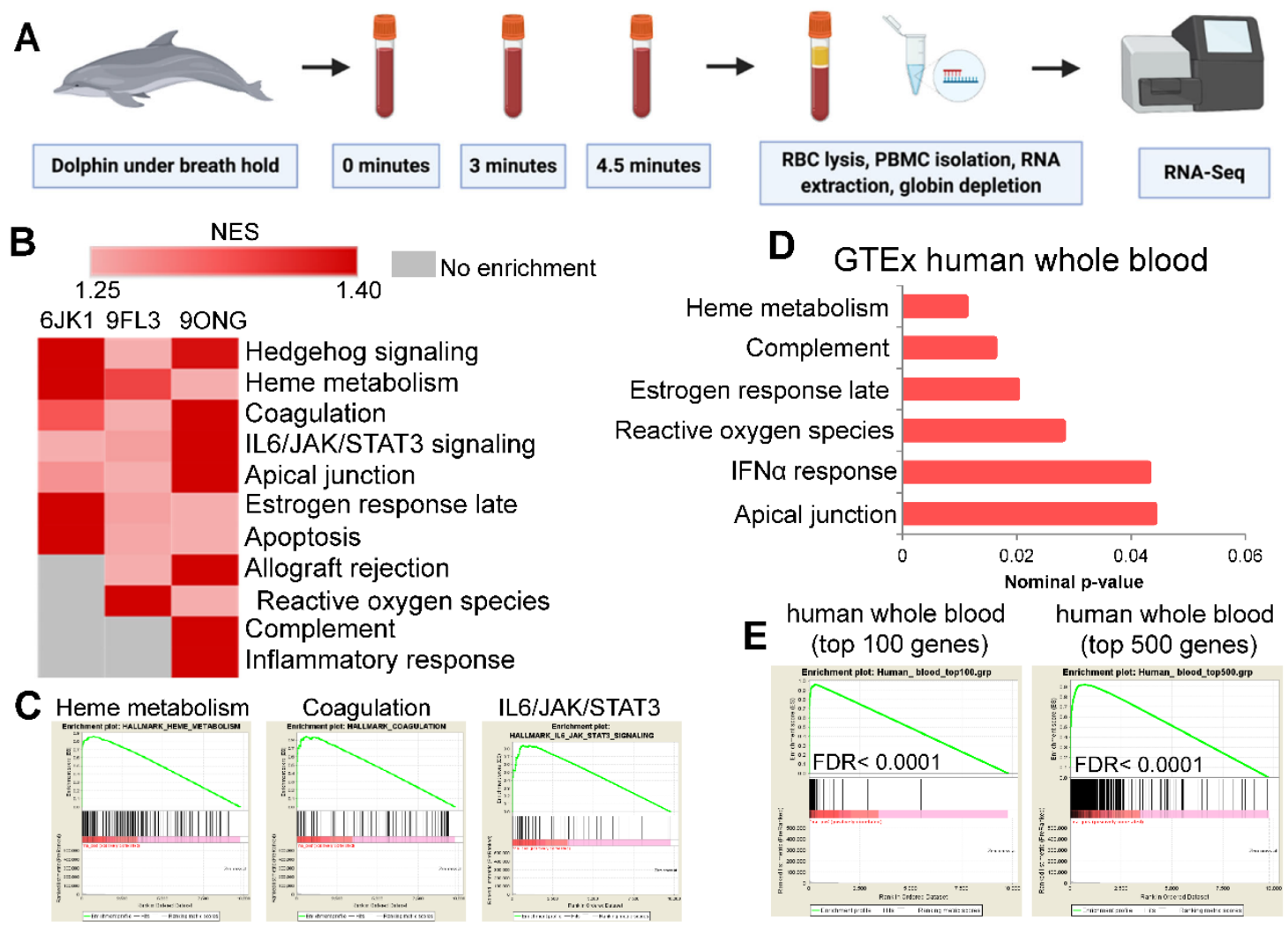

Figure 2. RNA-Seq from dolphin peripheral blood mononuclear cells reveals

enrichment of pathways similar to humans. A. Whole blood from dolphins undergoing fasted breath-holds at baseline (0-30 seconds), 3 minutes, and 4 1/2 minutes was collected from tail flukes and stored in PAXgene tubes for RNA extraction of peripheral blood mononuclear cells and RNA-Seq. B. Gene set enrichment analysis of baseline RNA-Seq data ranked by total expression pinpoints highly expressed relevant pathways. C. Enrichment plots for heme metabolism, coagulation, and IL6/JAK/STAT3 signaling from baseline dolphin RNA-Seq data. D. GSEA-based pathway enrichment from GTEx human whole blood RNASeq data ranked by total expression. E. GSEA enrichment plots comparing dolphin RNA-Seq data ranked by total expression with top 100 and top 500 expressed genes in human whole blood. 
221 PTGDR2, SIX5, DCN, ADAMTS12, and GLRX2 demonstrated upregulation and/or high

222 network connectivity (Figure 3B, C). We used GeneMANIA to infer transcription factor and

223 microRNA targets from this time-dependent network. The gene regulatory network produced

224 from these genes displayed enrichment in targets from several transcription factor families,

225 including GATA and the small, mothers against decapentaplegic (SMAD) families (Figure 3D),

226 both of which have been implicated in hematopoietic development and regulation (Blank and

227 Karlsson, 2011; Lentjes et al., 2016). Network inference also pinpointed enrichment of targets of

228 multiple microRNAs, including the miR148A/B/152 family, miR492, miR186, miR518A-2, the

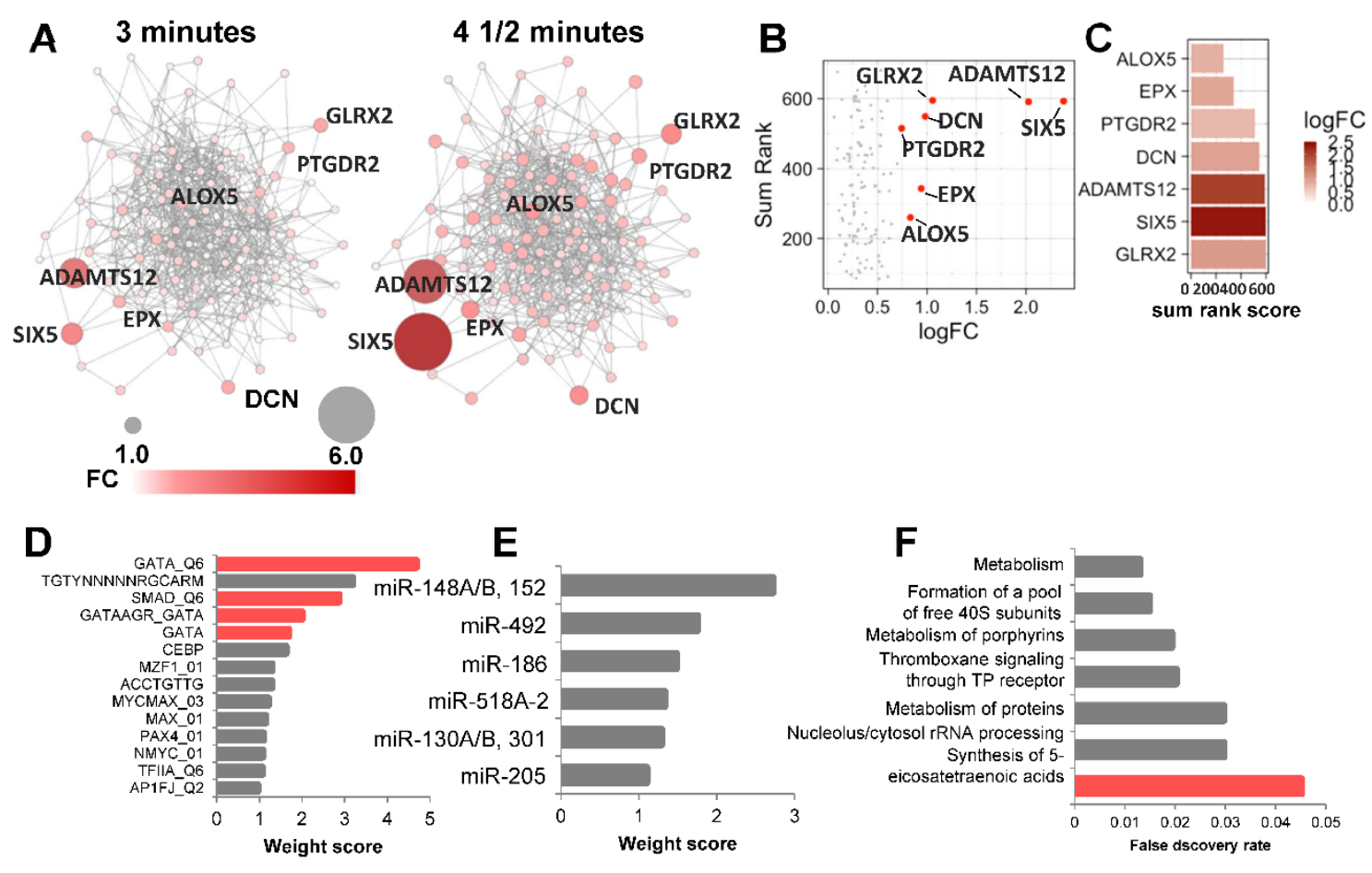

Figure 3. Time-dependent upregulation of gene regulatory pathways during dolphin

breath holding. A. Gene regulatory network formed by the time-dependent increases in mRNAs from baseline to 3 minutes and $4 \frac{1}{2}$ minutes. Fold changes for each gene over time are indicated by darker red and larger nodes. B. Network analysis of genes within a coexpression network with increased expression over time. C. Top genes with increased expression sorted by their network analysis parameters. D. GeneMANIA-based transcription factor inference pinpoints GATA and SMAD transcription factor targets within the timedependent network. E. MicroRNA enrichment inference based on the time-dependent network. F. Functional pathway enrichments for the time-dependent gene regulatory network. 
$229 \mathrm{miR} 130 \mathrm{~A} / \mathrm{B} / 301$ family, and miR205 (Figure 3E). Consistent with the identification of ALOX5

230 as a core network node, the network was functionally enriched the synthesis of 5-

231 eicosatetraenoic acid pathway, which is an initial step in the production of arachidonic acid by

\section{ALOX5 (Figure 3F).}

234 Arachidonate 5-Lipoxygenase (ALOX5) and subsequent lipoxygenase activity enhanced in

235 breath-holding dolphins. Based on the network analyses we focused on ALOX5 for further

236 validation. At the mRNA level, ALOX5 was one of just two genes, along with IL5RA, that was

237 significantly upregulated in all three individuals during breath-holding (Figure 4A, B).

238 Lipoxygenase assays from serum of three individual dolphins collected in 2019 revealed time-

239 dependent increases in lipoxygenase activity during breath-holding in all three individuals,

240 consistent with the RNA-Seq analyses (Figure 4C). Comparison of the timing of these molecular

241 changes with previously-published $f_{\mathrm{H}}$ measurements from the same dolphins demonstrated that

242 changes in gene expression and enzymatic activity were coincident with the expected timing of

243 bradycardia based on the heart rate data (Figure 4D). Overlay of the RNA-Seq data for ALOX5

244 expression with the heart rate data shows the upregulation of ALOX5 is concomitant with lower

245 heart rate (Figure 4E). 

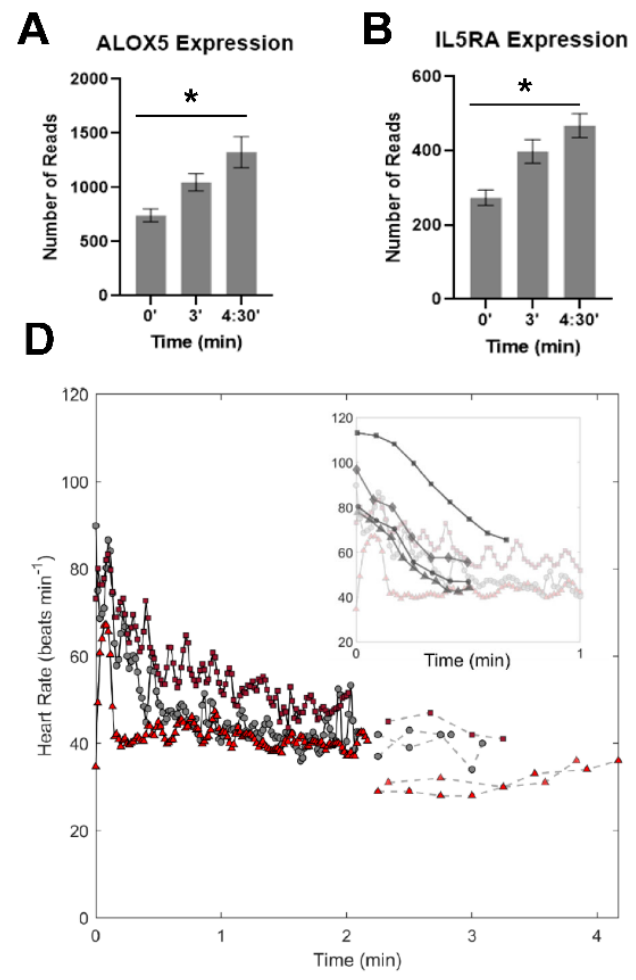
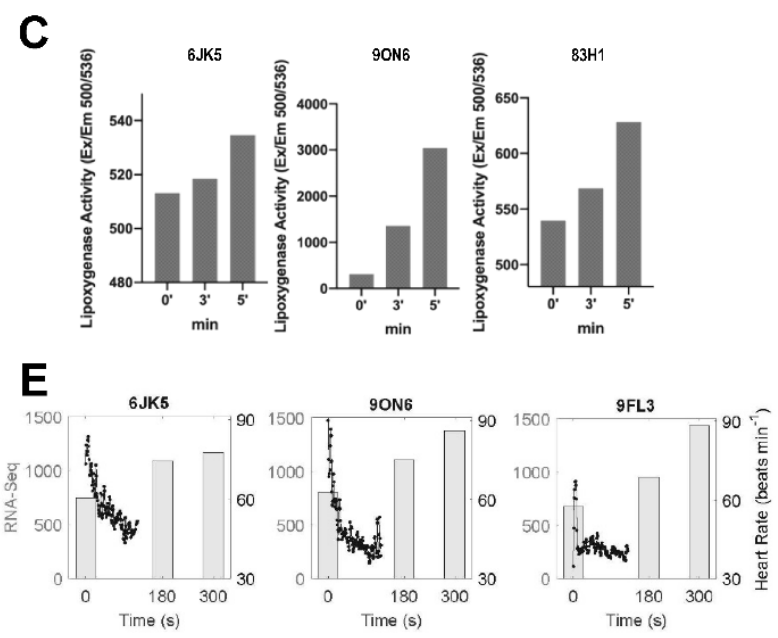

F

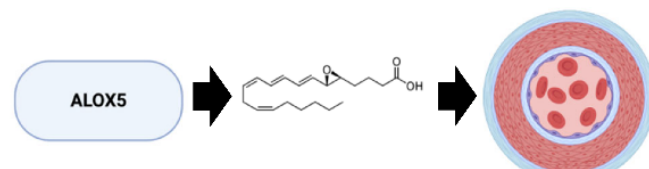

Figure 4. Dolphins induce ALOX5 activity during breath-holding. A. ALOX5 and B. IL5RA mRNA expression is significantly increased over time during breath-holding. C. Individual dolphin lipoxygenase activity in whole blood collected at an independent sampling date. D. Physiological measurements of heart rate for three individual dolphins (black lines from ECG data previously published in Blawas et al., 2020, dashed lines from echocardiogram data previously published in Fahlman et al., 2020) over time. Inset shows heart rate for humans performing breath-holds with facial immersion in water (dark gray in inset) overlaid on dolphin heart rate. Human heart rate traces were digitally extracted from Arnold, 1985; Andersson et al., 2004; and Shattock and Tipton, 2012. E. Overlay of heart rate data with ALOX activity in three individual dolphins. F. Hypothesized mechanism through which ALOX5 improves dive performance and mitigates ischemic stress tolerance.

\section{Discussion}

248 Dolphins and other cetaceans have evolved exquisite physiological adaptations to deal with the

249 challenges of a fully aquatic lifestyle including having a hydrodynamic shape to reduce drag

250 (Fish, 1993), counter-current heat exchangers for thermoregulation (Favilla and Costa, 2020; 
251 Pabst et al., 1999), and cardiorespiratory plasticity for exquisite management of circulation and

252 respiratory gases (Blawas et al., 2021; Fahlman et al., 2020b, 2020a, 2019b; Noren et al., 2012).

253 The well-known dive response, a suite of adaptations that support reduced aerobic metabolism

254 during diving, involves apnea, bradycardia, and peripheral vasoconstriction that assures

255 maintained mean arterial blood pressure as blood flow to peripheral tissues is reduced and allows

256 regulation of perfusion to conserve oxygen-rich blood for the brain and heart. To maintain a

257 constant mean arterial blood pressure and prevent hypertension, these adaptations must work in

258 concert to ensure efficient autoregulation; however, extended dives also result in frequent events

259 of ischemia and hypoxia (Fahlman et al., 2019a; McKnight et al., 2019; Ridgway et al., 1969).

260 While these cardiorespiratory adaptations have been studied from the perspective of the changes

261 in $f_{\mathrm{H}}$ associated with diving, we are not aware of any study that has measured blood pressure in

262 voluntarily diving cetaceans. Thus, little is known about whether dolphins are able to maintain

263 constant mean arterial blood pressure throughout the breath-hold. In addition, knowledge of the

264 molecular adaptations that contribute to enhanced tolerance to hypoxia and ischemic stress, and

265 that prevent reperfusion injury during and following a dive, is rudimentary at best. To address

266 this lack of understanding, we combined an integrated genomics and systems-level analysis of

267 breath-hold responses at the molecular level with existing physiological measurements to define

268 the molecular responses to breath-holding in dolphins.

269 While this study is limited by a small sample size and relatively short breath-hold

270 durations, our analyses identified candidate genes and pathways with time-dependent changes in

271 expression throughout the breath-holds that were validated in functional studies using

272 independently-collected samples and assays. Consequently, these results provide evidence for

273 fine-scale cardiovascular control in bottlenose dolphins at the genetic level, and suggest that 
274 dolphins may manage blood pressure changes during diving using both autonomic and molecular

275 pathways to regulate peripheral vasomotor control. Notably, these molecular changes occurred

276 within the calculated aerobic dive limit (cADL) of bottlenose dolphins - the duration of a dive

277 that can be sustained without requiring anaerobic respiration at the cellular level which has been

278 estimated to be 6.5 minutes (Fahlman et al., 2018). This suggests that changes in gene

279 expression may operate on a short enough time-scale that they could play a role in driving the

280 physiological changes that are observed during the breath-hold and recovery. It is also worth

281 considering the possibility that changes in gene expression could occur to support specific

282 physiological responses to diving during a dive, and that this gene expression differs when the

283 animal is at the surface. Future studies will be focused on using novel technologies, such as

284 GRO-Seq (Lopes et al., 2017) and others to measure nascent mRNAs, as well as measuring later

285 time points to understand the changes that occur upon recovery from breath-holds.

To provide physiological context for these molecular alterations on the time scales

288 same individual dolphins during submerged breath-holds (Blawas et al., 2021; Fahlman et al.,

289 2020b). If we assume that the appearance of vasoconstriction is coincident with bradycardia, our

290 data provide evidence of an increase in the expression of a gene, ALOX5, known to promote

291 vasoconstriction coincident with the onset of vasoconstriction. Vasoconstriction, or a narrowing

292 of the blood vessels, has been suggested as a mechanism by which marine mammals during

293 forced dives have been observed to optimize the use of onboard oxygen stores in the blood and

294 muscle (Davis and Kanatous, 1999; Scholander and Grinnell, 1942; Zapol et al., 1979). Given

295 the long assumed link between vasoconstriction and bradycardia in marine mammals, the rapid

296 bradycardia we observed suggests that vasoconstriction was occurring in the dolphins in this 
study during breath-holds (Hochachka, 1981; Van Citters et al., 1965). We found that changes in gene expression occurred in all animals during the 5-minute breath-hold trials and that the same gene families that were upregulated in the dolphins during breath-holds help manage vasoconstriction in mice (Ichinose et al., 2001) and humans (Friedman et al., 1984). act synergistically with the cardiac response to breath-holding in bottlenose dolphins. Specifically, we identified a suite of candidate genes that may support peripheral vasoconstriction and provide defense against ischemic and hypoxic stress in dolphins, including the GATA and SMAD transcription factors, several microRNAs, a disintegrin and metalloproteinase with thrombospondin motifs 12 (ADAMTS12), mitochondrial glutaredoxin-2

307 (Glrx2), and ALOX5. Interestingly, many of these factors play known roles in regulating 308 hypoxia, hematopoiesis, and ischemic stress responses. For example, the GATA transcription 309 factor family is an important modulator of hematopoietic development of T lymphocytes, mast 310 cells, and erythrocytes (Lentjes et al., 2016). Likewise, the SMAD family regulates

311 hematopoietic stem cells (Blank and Karlsson, 2011). Of the microRNAs identified from our 312 analysis of target enrichments, nearly all have been shown to be protective against ischemia313 induced cell death, including miR148A (Zheng et al., 2018), miR492 (Guo et al., 2020), miR186

314 (Bostjancic et al., 2009; Li et al., 2013; Wang et al., 2018), miR130 (Lu et al., 2015), and 315 miR205 (Chen et al., 2019). At the protein-coding gene level, ADAMTS12 genetic variation is 316 associated with pediatric stroke (Witten et al., 2020), GLRX2 is implicated in neuroprotection

317 during hypoxia and ischemia (Romero et al., 2015), and ALOX5 is known to be induced by 318 hypoxia (Porter et al., 2014) and mediates the production of leukotrienes, which induce 319 bronchoconstriction and vasoconstriction (Poeckel and Funk, 2010). In addition, both ALOX5 
and IL5RA have been identified as susceptibility genes associated with asthma and asthmatic

321 inflammation in humans (Cheong et al., 2005; Mougey et al., 2013), and a monoclonal antibody

322 to the IL5RA ligand, IL5, is FDA-approved for the treatment of severe eosinophilic asthma

323 (Fala, 2016; Pavord et al., 2012). Given the intricate connection between molecular control and

324 physiologic function to manage ischemia, hypoxia, and inflammatory responses in humans and

325 rodent models, (Bartels et al., 2013) it is intriguing to speculate as to how dolphins and other

326 marine mammals may uncouple or leverage these interconnected processes for improved

327 tolerance to ischemic/hypoxic stress without the pathological consequences associated with

328 hyper-stimulation of these processes.

These results demonstrate that the ALOX5 pathway is upregulated in bottlenose dolphins

330 during breath-holds and offer a potential mechanism for maintaining elevated peripheral

331 resistance through vasoconstriction, which helps manage blood distribution and the available

332 oxygen for critical organs. We suggest that the upregulation of ALOX5 could support a genetic

333 response that is secondary to the autonomic response during diving to prolong vasoconstriction

334 and maintain mean arterial blood pressure during extended periods of submersion (Figure 4F).

335 Interestingly, the changes we observed occurred within the cADL of the species, indicating that

336 fluctuations in gene expression could be occurring during regular dives. These fast-acting

337 changes in gene expression that support vasoconstriction provide evidence for fine-scale control

338 of perfusion in dolphins and an ability to maintain constant blood pressure, as is observed during

339 forced dives of pinnipeds (Blix et al., 1976; Zapol et al., 1979). Additionally, the data show that

340 during the breath-holds a large suite of candidate genes are upregulated that may support an

341 increased tolerance to the hypoxia and ischemic conditions that are expected to arise in some

342 peripheral tissues during diving. By interpreting these molecular data in the context of the 
343 physiological changes known to occur in bottlenose dolphins during a breath-hold, we have

344 identified several genes that are upregulated during apnea in dolphins and may be an additional

345 mechanism to reinforce vasoconstriction while also providing defense against the hypoxia and

346 ischemia resulting from this response.

347 By examining molecular data through a physiological lens, these data connect the cellular

348 and tissue-level responses of dolphins to apnea to understand whether the bottlenose dolphin

349 may be genetically tuned to dive and withstand the hypoxia and the potential implications of this

350 to translational medicine. Our results uncover potential candidates at the intersection of ischemia,

351 hypoxia, and vasoconstriction that may contribute to the exquisite adaptation of dolphins and

352 other marine mammals to life in the ocean.

354 Abbreviations List

355 cADL, calculated aerobic dive limit

356 ALOX5, Arachidonate 5-Lipoxygenase

357 GSEA, Gene Set Enrichment Analysis

$358 f_{\mathrm{H}}$, heart rate

359 IL5RA, Interleukin 5 receptor, alpha

360 PBMC, peripheral blood mononuclear cells

\section{Acknowledgments}

363 The authors wish to thank the marine mammal specialists, veterinarians, and dolphins at Dolphin

364 Quest, Oahu, The Duke Sequencing and Genomics Technologies Shared Resource, and the Duke

365 Genomics Analysis and Bioinformatics Shared Resource. The authors also thank the Laboratory 
of Dr. Peter Hoffman at The University of Hawai'i for providing a centrifuge and other

and Mallissa Vuong for their role in data collection.

\section{References}

Allen, K.N., Vázquez-Medina, J.P., 2019. Natural Tolerance to Ischemia and Hypoxemia in Diving Mammals: A Review. Front. Physiol. 10. https://doi.org/10.3389/fphys.2019.01199 throughput sequencing data. Bioinformatics 31, 166-169. https://doi.org/10.1093/bioinformatics/btu638

Bagchi, A., Batten, A.J., Levin, M., Allen, K.N., Fitzgerald, M.L., Hückstädt, L.A., Costa, D.P., Buys, E.S., Hindle, A.G., 2018. Intrinsic anti-inflammatory properties in the serum of two species of deep-diving seal. Journal of Experimental Biology 221. https://doi.org/10.1242/jeb.178491

Bartels, K., Grenz, A., Eltzschig, H.K., 2013. Hypoxia and inflammation are two sides of the same coin. Proc Natl Acad Sci U S A 110, 18351-18352. https://doi.org/10.1073/pnas.1318345110

Bi, J., Hu, B., Zheng, J., Wang, J., Xiao, W., Wang, D., 2015. Characterization of the hypoxiainducible factor 1 alpha gene in the sperm whale, beluga whale, and Yangtze finless porpoise. Mar Biol 162, 1201-1213. https://doi.org/10.1007/s00227-015-2662-4

Blank, U., Karlsson, S., 2011. The role of Smad signaling in hematopoiesis and translational hematology. Leukemia 25, 1379-1388. https://doi.org/10.1038/leu.2011.95

Blawas, A.M., Nowacek, D.P., Allen, A.S., Rocho-Levine, J., Fahlman, A., 2021. Respiratory sinus arrhythmia and submersion bradycardia in bottlenose dolphins (Tursiops truncatus). Journal of Experimental Biology. https://doi.org/10.1242/jeb.234096

Blix, A.S., Kjekshus, J.K., Enge, I., Bergan, A., 1976. Myocardial Blood Flow in the Diving Seal. Acta Physiologica Scandinavica 96, 277-280. https://doi.org/10.1111/j.17481716.1976.tb10196.x

Bona, E., Andersson, A.-L., Blomgren, K., Gilland, E., Puka-Sundvall, M., Gustafson, K., Hagberg, H., 1999. Chemokine and Inflammatory Cell Response to Hypoxia-Ischemia in Immature Rats. Pediatric Research 45, 500-509. https://doi.org/10.1203/00006450199904010-00008

Bostjancic, E., Zidar, N., Glavac, D., 2009. MicroRNA microarray expression profiling in human myocardial infarction. Dis Markers 27, 255-268. https://doi.org/10.3233/DMA-20090671 
Breskovic, T., Uglesic, L., Zubin, P., Kuch, B., Kraljevic, J., Zanchi, J., Ljubkovic, M., Sieber, A., Dujic, Z., 2011. Cardiovascular changes during underwater static and dynamic breath-hold dives in trained divers. J Appl Physiol (1985) 111, 673-678. https://doi.org/10.1152/japplphysiol.00209.2011

Chen, W., Ruan, Y., Zhao, S., Ning, J., Rao, T., Yu, W., Zhou, X., Liu, C., Qi, Y., Cheng, F., 2019. MicroRNA-205 inhibits the apoptosis of renal tubular epithelial cells via the PTEN/Akt pathway in renal ischemia-reperfusion injury. Am J Transl Res 11, 73647375.

Cheong, H.S., Kim, L.H., Park, B.L., Choi, Y.H., Park, H.-S., Hong, S.-J., Choi, B.W., Park, C.S., Shin, H.D., 2005. Association analysis of interleukin 5 receptor alpha subunit (IL5RA) polymorphisms and asthma. J Hum Genet 50, 628-634. https://doi.org/10.1007/s10038-005-0304-2

Choi, D.W., 1996. Ischemia-induced neuronal apoptosis. Current Opinion in Neurobiology 6, 667-672. https://doi.org/10.1016/S0959-4388(96)80101-2

Davis, R.W., Kanatous, S.B., 1999. Convective oxygen transport and tissue oxygen consumption in Weddell seals during aerobic dives. Journal of Experimental Biology 202, 1091-1113.

Dobin, A., Davis, C.A., Schlesinger, F., Drenkow, J., Zaleski, C., Jha, S., Batut, P., Chaisson, M., Gingeras, T.R., 2013. STAR: ultrafast universal RNA-seq aligner. Bioinformatics 29, 15-21. https://doi.org/10.1093/bioinformatics/bts635

Eltzschig, H.K., Carmeliet, P., 2011. Hypoxia and Inflammation. New England Journal of Medicine 364, 656-665. https://doi.org/10.1056/NEJMra0910283

Fahlman, A., Brodsky, M., Miedler, S., Dennison, S., Ivančić, M., Levine, G., Rocho-Levine, J., Manley, M., Rocabert, J., Borque-Espinosa, A., 2019a. Ventilation and gas exchange before and after voluntary static surface breath-holds in clinically healthy bottlenose dolphins, Tursiops truncatus. Journal of Experimental Biology 222. https://doi.org/10.1242/jeb.192211

Fahlman, A., Cozzi, B., Manley, M., Jabas, S., Malik, M., Blawas, A., Janik, V., 2020a. Conditioned variation in heart rate during static breath-holds in the bottlenose dolphin (Tursiops truncatus). Front. Physiol. 11. https://doi.org/10.3389/fphys.2020.604018

Fahlman, A., Hooker, S.K., Olszowka, A., Bostrom, B.L., Jones, D.R., 2009. Estimating the effect of lung collapse and pulmonary shunt on gas exchange during breath-hold diving: the Scholander and Kooyman legacy. Respir Physiol Neurobiol 165, 28-39. https://doi.org/10.1016/j.resp.2008.09.013

Fahlman, A., Jensen, F.H., Tyack, P.L., Wells, R.S., 2018. Modeling Tissue and Blood Gas Kinetics in Coastal and Offshore Common Bottlenose Dolphins, Tursiops truncatus. Front. Physiol. 9. https://doi.org/10.3389/fphys.2018.00838

Fahlman, A., Miedler, S., Marti-Bonmati, L., Fernandez, D.F., Caballero, P.M., Arenarez, J., Rocho-Levine, J., Robeck, T., Blawas, A., 2020b. Cardiorespiratory coupling in cetaceans; a physiological strategy to improve gas exchange? Journal of Experimental Biology. https://doi.org/10.1242/jeb.226365

Fahlman, A., Miedler, S., Rocho-Levine, J., Jabois, A., Arenarez, J., Marti-Bonmati, L., GarcíaPárraga, D., Cauture, F., 2019b. Re-evaluating the significance of the dive response during voluntary surface apneas in the bottlenose dolphin, Tursiops truncatus. Scientific Reports 9. https://doi.org/10.1038/s41598-019-45064-8 
Fala, L., 2016. Nucala (Mepolizumab): First IL-5 Antagonist Monoclonal Antibody FDA Approved for Maintenance Treatment of Patients with Severe Asthma. Am Health Drug Benefits 9, 106-110.

Favilla, A.B., Costa, D.P., 2020. Thermoregulatory Strategies of Diving Air-Breathing Marine Vertebrates: A Review. Front. Ecol. Evol. 8. https://doi.org/10.3389/fevo.2020.555509

Fish, F.E., 1993. Power output and propulsive efficiency of swimming bottlenose dolphins (Tursiops truncatus. J. Exp. Biol 179-193.

Franz, M., Rodriguez, H., Lopes, C., Zuberi, K., Montojo, J., Bader, G.D., Morris, Q., 2018. GeneMANIA update 2018. Nucleic Acids Res 46, W60-W64. https://doi.org/10.1093/nar/gky311

Friedman, Z., Lunyong, V.E., Courtney, J., Smith, H., Berkowitz, P., Sun, F., 1984. Prostaglandin formation in the isolated human ductus arteriosus, aorta, pulmonary and umbilical arteries. Prostaglandins Leukot Med 14, 279-286. https://doi.org/10.1016/0262-1746(84)90211-7

Gooden, B.A., 1994. Mechanism of the human diving response. Integr Physiol Behav Sci 29, 616. https://doi.org/10.1007/BF02691277

Gottlieb, R.A., Engler, R.L., 1999. Apoptosis in Myocardial Ischemia-Reperfusion. Annals of the New York Academy of Sciences 874, 412-426. https://doi.org/10.1111/j.17496632.1999.tb09255.x

Guo, L.-L., Chen, H.-H., Qu, F.-C., Lu, Q.-H., 2020. Clinical significance of miR-492 in peripheral blood of acute myocardial infarction. Eur Rev Med Pharmacol Sci 24, 90419045. https://doi.org/10.26355/eurrev_202009_22849

Hindle, A.G., 2020. Diving deep: Understanding the genetic components of hypoxia tolerance in marine mammals. Journal of Applied Physiology. https://doi.org/10.1152/japplphysiol.00846.2019

Hochachka, P.W., 1981. Brain, Lung, and Heart Functions during Diving and Recovery. Science 212, 509-514.

Huber, W., Carey, V.J., Gentleman, R., Anders, S., Carlson, M., Carvalho, B.S., Bravo, H.C., Davis, S., Gatto, L., Girke, T., Gottardo, R., Hahne, F., Hansen, K.D., Irizarry, R.A., Lawrence, M., Love, M.I., MacDonald, J., Obenchain, V., Oleś, A.K., Pagès, H., Reyes, A., Shannon, P., Smyth, G.K., Tenenbaum, D., Waldron, L., Morgan, M., 2015. Orchestrating high-throughput genomic analysis with Bioconductor. Nat Methods 12, 115-121. https://doi.org/10.1038/nmeth.3252

Ichinose, F., Zapol, W.M., Sapirstein, A., Ullrich, R., Tager, A.M., Coggins, K., Jones, R., Bloch, K.D., 2001. Attenuation of hypoxic pulmonary vasoconstriction by endotoxemia requires 5-lipoxygenase in mice. Circ Res 88, 832-838. https://doi.org/10.1161/hh0801.089177

Irving, L., Scholander, P.F., Grinnell, S.W., 1941. The respiration of the porpoise, tursiops truncatus. Journal of Cellular and Comparative Physiology 17, 145-168. https://doi.org/10.1002/jcp.1030170203

Johnson, P., Elsner, R., Zenteno-Savín, T., 2005. Hypoxia-inducible factor 1 proteomics and diving adaptations in ringed seal. Free Radical Biology and Medicine 39, 205-212. https://doi.org/10.1016/j.freeradbiomed.2005.03.008

Johnson, P., Elsner, R., Zenteno-Savín, T., 2004. Hypoxia-Inducible Factor in Ringed Seal (Phoca hispida) Tissues. Free Radical Research 38, 847-854. https://doi.org/10.1080/10715760410001725526 
494

Kersey, P.J., Staines, D.M., Lawson, D., Kulesha, E., Derwent, P., Humphrey, J.C., Hughes, D.S.T., Keenan, S., Kerhornou, A., Koscielny, G., Langridge, N., McDowall, M.D., Megy, K., Maheswari, U., Nuhn, M., Paulini, M., Pedro, H., Toneva, I., Wilson, D., Yates, A., Birney, E., 2012. Ensembl Genomes: an integrative resource for genome-scale data from non-vertebrate species. Nucleic Acids Res. 40, D91-97. https://doi.org/10.1093/nar/gkr895

Kooyman, G.L., Ponganis, P.J., 1998. The physiological basis of diving to depth: birds and mammals. Annu. Rev. Physiol. 60, 19-32. https://doi.org/10.1146/annurev.physiol.60.1.19

Krueger, F., 2020. FelixKrueger/TrimGalore.

Lentjes, M.H.F.M., Niessen, H.E.C., Akiyama, Y., de Bruïne, A.P., Melotte, V., van Engeland, M., 2016. The emerging role of GATA transcription factors in development and disease. Expert Rev Mol Med 18, e3. https://doi.org/10.1017/erm.2016.2

Li, C., Fang, Z., Jiang, T., Zhang, Q., Liu, C., Zhang, C., Xiang, Y., 2013. Serum microRNAs profile from genome-wide serves as a fingerprint for diagnosis of acute myocardial infarction and angina pectoris. BMC Med Genomics 6, 16. https://doi.org/10.1186/17558794-6-16

Lopes, R., Agami, R., Korkmaz, G., 2017. GRO-seq, A Tool for Identification of Transcripts Regulating Gene Expression. Methods Mol Biol 1543, 45-55. https://doi.org/10.1007/978-1-4939-6716-2_3

Love, M.I., Huber, W., Anders, S., 2014. Moderated estimation of fold change and dispersion for RNA-seq data with DESeq2. Genome Biology 15, 550. https://doi.org/10.1186/s13059014-0550-8

Lu, C., Wang, X., Ha, T., Hu, Y., Liu, L., Zhang, X., Yu, H., Miao, J., Kao, R., Kalbfleisch, J., Williams, D., Li, C., 2015. Attenuation of cardiac dysfunction and remodeling of myocardial infarction by microRNA-130a are mediated by suppression of PTEN and activation of PI3K dependent signaling. J Mol Cell Cardiol 89, 87-97. https://doi.org/10.1016/j.yjmcc.2015.10.011

Martin, M., 2011. Cutadapt removes adapter sequences from high-throughput sequencing reads. EMBnet.journal 17, 10-12. https://doi.org/10.14806/ej.17.1.200

McKnight, J.C., Bennett, K.A., Bronkhorst, M., Russell, D.J.F., Balfour, S., Milne, R., Bivins, M., Moss, S.E.W., Colier, W., Hall, A.J., Thompson, D., 2019. Shining new light on mammalian diving physiology using wearable near-infrared spectroscopy. PLOS Biology 17, e3000306. https://doi.org/10.1371/journal.pbio.3000306

Mirceta, S., Signore, A.V., Burns, J.M., Cossins, A.R., Campbell, K.L., Berenbrink, M., 2013. Evolution of Mammalian Diving Capacity Traced by Myoglobin Net Surface Charge. Science 340, 1234192-1234192. https://doi.org/10.1126/science. 1234192

Mootha, V.K., Lindgren, C.M., Eriksson, K.-F., Subramanian, A., Sihag, S., Lehar, J., Puigserver, P., Carlsson, E., Ridderstråle, M., Laurila, E., Houstis, N., Daly, M.J., Patterson, N., Mesirov, J.P., Golub, T.R., Tamayo, P., Spiegelman, B., Lander, E.S., Hirschhorn, J.N., Altshuler, D., Groop, L.C., 2003. PGC-1alpha-responsive genes involved in oxidative phosphorylation are coordinately downregulated in human diabetes. Nat. Genet. 34, 267-273. https://doi.org/10.1038/ng1180

Mougey, E., Lang, J.E., Allayee, H., Teague, W.G., Dozor, A.J., Wise, R.A., Lima, J.J., 2013. ALOX5 polymorphism associates with increased leukotriene production and reduced 
lung function and asthma control in children with poorly controlled asthma. Clin Exp Allergy 43, 512-520. https://doi.org/10.1111/cea.12076

Murdoch, C., Muthana, M., Lewis, C.E., 2005. Hypoxia Regulates Macrophage Functions in Inflammation. The Journal of Immunology 175, 6257-6263. https://doi.org/10.4049/jimmunol.175.10.6257

Nery, M.F., Arroyo, J.I., Opazo, J.C., 2013. Accelerated evolutionary rate of the myoglobin gene in long-diving whales. J. Mol. Evol. 76, 380-387. https://doi.org/10.1007/s00239-0139572-1

Noren, S.R., Kendall, T., Cuccurullo, V., Williams, T.M., 2012. The dive response redefined: underwater behavior influences cardiac variability in freely diving dolphins. Journal of Experimental Biology 215, 2735-2741. https://doi.org/10.1242/jeb.069583

Nowbar, A.N., Gitto, M., Howard, J.P., Francis, D.P., Al-Lamee, R., 2019. Mortality From Ischemic Heart Disease. Circulation: Cardiovascular Quality and Outcomes 12, e005375. https://doi.org/10.1161/CIRCOUTCOMES.118.005375

Pabst, D.A., Rommel, S.A., McLellan, W.A., 1999. Functional anatomy of marine mammals, in: Biology of Marine Mammals.

Panneton, M.W., 2013. The Mammalian Diving Response: An Enigmatic Reflex to Preserve Life? Physiology 28, 284-297. https://doi.org/10.1152/physiol.00020.2013

Pavord, I.D., Korn, S., Howarth, P., Bleecker, E.R., Buhl, R., Keene, O.N., Ortega, H., Chanez, P., 2012. Mepolizumab for severe eosinophilic asthma (DREAM): a multicentre, doubleblind, placebo-controlled trial. Lancet 380, 651-659. https://doi.org/10.1016/S01406736(12)60988-X

Poeckel, D., Funk, C.D., 2010. The 5-lipoxygenase/leukotriene pathway in preclinical models of cardiovascular disease. Cardiovasc Res 86, 243-253. https://doi.org/10.1093/cvr/cvq016

Porter, K.M., Kang, B.-Y., Adesina, S.E., Murphy, T.C., Hart, C.M., Sutliff, R.L., 2014. Chronic hypoxia promotes pulmonary artery endothelial cell proliferation through $\mathrm{H} 2 \mathrm{O} 2$-induced 5-lipoxygenase. PLoS One 9, e98532. https://doi.org/10.1371/journal.pone.0098532

R Core Team, 2020. R: A Language and Environment for Statistical Computing. R Foundation for Statistical Computing, Vienna, Austria.

Ridgway, S.H., Scronce, B.L., Kanwisher, J., 1969. Respiration and Deep Diving in the Bottlenose Porpoise. Science 166, 1651-1654.

Romero, J.I., Hanschmann, E.-M., Gellert, M., Eitner, S., Holubiec, M.I., Blanco-Calvo, E., Lillig, C.H., Capani, F., 2015. Thioredoxin 1 and glutaredoxin 2 contribute to maintain the phenotype and integrity of neurons following perinatal asphyxia. Biochim Biophys Acta 1850, 1274-1285. https://doi.org/10.1016/j.bbagen.2015.02.015

Scholander, P.F., 1940. Experimental Investigations on the Respiratory Function in Diving Mammals and Birds. Hvalradets Skrifter.

Scholander, P.F., Grinnell, S.W., 1942. Aerobic and anaerobic changes in seal muscles during diving 11.

Shannon, P., Markiel, A., Ozier, O., Baliga, N.S., Wang, J.T., Ramage, D., Amin, N., Schwikowski, B., Ideker, T., 2003. Cytoscape: a software environment for integrated models of biomolecular interaction networks. Genome Res 13, 2498-2504. https://doi.org/10.1101/gr.1239303

Subramanian, A., Tamayo, P., Mootha, V.K., Mukherjee, S., Ebert, B.L., Gillette, M.A., Paulovich, A., Pomeroy, S.L., Golub, T.R., Lander, E.S., Mesirov, J.P., 2005. Gene set enrichment analysis: a knowledge-based approach for interpreting genome-wide 
expression profiles. Proc Natl Acad Sci U S A 102, 15545-15550. https://doi.org/10.1073/pnas.0506580102

Taboni, A., Fagoni, N., Moia, C., Vinetti, G., Ferretti, G., 2019. Gas exchange and cardiovascular responses during breath-holding in divers. Respir Physiol Neurobiol 267, 27-34. https://doi.org/10.1016/j.resp.2019.06.002

Tian, R., Wang, Z., Niu, X., Zhou, K., Xu, S., Yang, G., 2016. Evolutionary Genetics of Hypoxia Tolerance in Cetaceans during Diving. Genome Biol Evol 8, 827-839. https://doi.org/10.1093/gbe/evw037

Tian, R., Yin, D., Liu, Y., Seim, I., Xu, S., Yang, G., 2017. Adaptive Evolution of Energy Metabolism-Related Genes in Hypoxia-Tolerant Mammals. Front. Genet. 8. https://doi.org/10.3389/fgene.2017.00205

Tift, M.S., Ponganis, P.J., Crocker, D.E., 2014. Elevated carboxyhemoglobin in a marine mammal, the northern elephant seal. Journal of Experimental Biology 217, 1752-1757. https://doi.org/10.1242/jeb.100677

Van Citters, R.L., Franklin, D.L., Smith, O.A., Watson, N.W., Elsner, R.W., 1965. Cardiovascular adaptations to diving in the northern elephant seal Mirounga angustirostris. Comparative Biochemistry and Physiology 16, 267-276. https://doi.org/10.1016/0010-406X(65)90324-5

Wang, R., Bao, H., Zhang, S., Li, R., Chen, L., Zhu, Y., 2018. miR-186-5p Promotes Apoptosis by Targeting IGF-1 in SH-SY5Y OGD/R Model. Int J Biol Sci 14, 1791-1799. https://doi.org/10.7150/ijbs.25352

Witten, A., Rühle, F., de Witt, M., Barysenka, A., Stach, M., Junker, R., Nowak-Göttl, U., Stoll, M., 2020. ADAMTS12, a new candidate gene for pediatric stroke. PLoS One 15, e0237928. https://doi.org/10.1371/journal.pone.0237928

World Health Organization, 2018. Global Health Estimates 2016: Deaths by Cause, Age, Sex, by Country and by Region, 2000- 2016. Geneva.

Yim, H.-S., Cho, Y.S., Guang, X., Kang, S.G., Jeong, J.-Y., Cha, S.-S., Oh, H.-M., Lee, Jae-Hak, Yang, E.C., Kwon, K.K., Kim, Y.J., Kim, T.W., Kim, W., Jeon, J.H., Kim, S.-J., Choi, D.H., Jho, S., Kim, H.-M., Ko, J., Kim, H., Shin, Y.-A., Jung, H.-J., Zheng, Y., Wang, Z., Chen, Y., Chen, M., Jiang, A., Li, E., Zhang, S., Hou, H., Kim, T.H., Yu, L., Liu, S., Ahn, K., Cooper, J., Park, S.-G., Hong, C.P., Jin, W., Kim, H.-S., Park, C., Lee, K., Chun, S., Morin, P.A., O’Brien, S.J., Lee, H., Kimura, J., Moon, D.Y., Manica, A., Edwards, J., Kim, B.C., Kim, S., Wang, J., Bhak, J., Lee, H.S., Lee, Jung-Hyun, 2014. Minke whale genome and aquatic adaptation in cetaceans. Nature Genetics 46, 88-92. https://doi.org/10.1038/ng.2835

Zapol, W.M., Liggins, G.C., Schneider, R.C., Qvist, J., Snider, M.T., Creasy, R.K., Hochachka, P.W., 1979. Regional blood flow during simulated diving in the conscious Weddell seal. Journal of Applied Physiology 47, 968-973. https://doi.org/10.1152/jappl.1979.47.5.968

Zheng, D., Li, Z., Wei, X., Liu, R., Shen, A., He, D., Tang, C., Wu, Z., 2018. Role of miR-148a in Mitigating Hepatic Ischemia-Reperfusion Injury by Repressing the TLR4 Signaling Pathway via Targeting CaMKII $\alpha$ in Vivo and in Vitro. Cell Physiol Biochem 49, 2060 2072. https://doi.org/10.1159/000493716

Zhou, X., Sun, D., Guang, X., Ma, S., Fang, X., Mariotti, M., Nielsen, R., Gladyshev, V.N., Yang, G., 2018. Molecular Footprints of Aquatic Adaptation Including Bone Mass Changes in Cetaceans. Genome Biol Evol 10, 967-975. https://doi.org/10.1093/gbe/evy062 
bioRxiv preprint doi: https://doi.org/10.1101/2021.01.20.425775; this version posted February 26, 2021. The copyright holder for this preprint (which was not certified by peer review) is the author/funder, who has granted bioRxiv a license to display the preprint in perpetuity. It is made available under aCC-BY-NC-ND 4.0 International license.

631 Zhu, K., Ge, D., Wen, Z., Xia, L., Yang, Q., 2018. Evolutionary Genetics of Hypoxia and Cold 632 Tolerance in Mammals. J Mol Evol 86, 618-634. https://doi.org/10.1007/s00239-018$633 \quad 9870-8$

634 

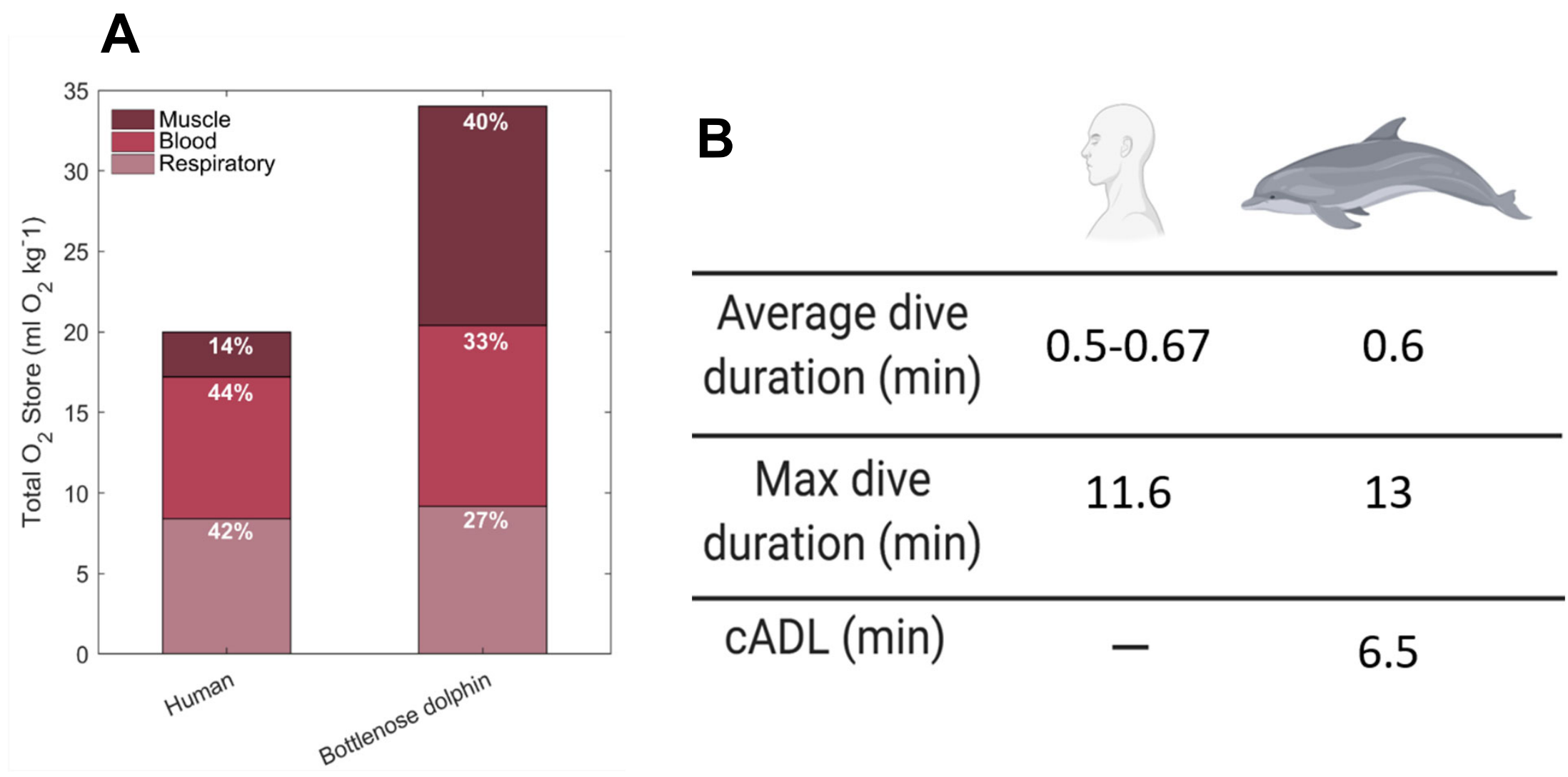
A

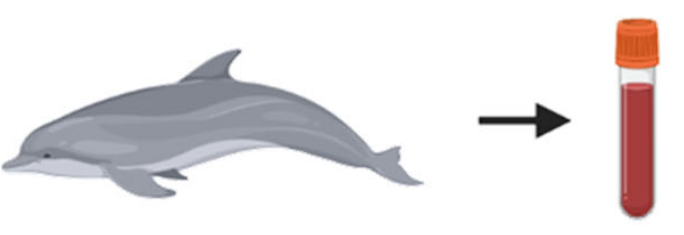

Dolphin under breath hold

0 minutes

3 minutes

4.5 minutes

RBC lysis, PBMC isolation, RNA extraction, globin depletion

RNA-Seq

B

NES

1.25

6JK1 9FL3 9ONG

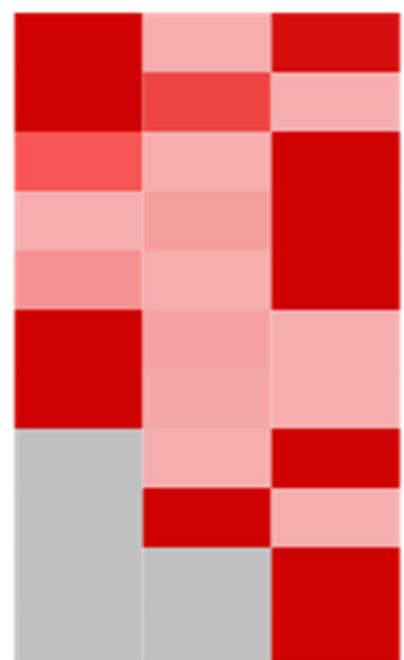

Hedgehog signaling Heme metabolism

Coagulation

IL6/JAK/STAT3 signaling

Apical junction

Estrogen response late

Apoptosis

Allograft rejection

Reactive oxygen species

Complement

Inflammatory response

C Heme metabolism

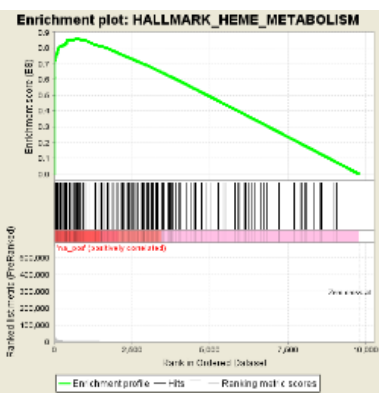

Coagulation

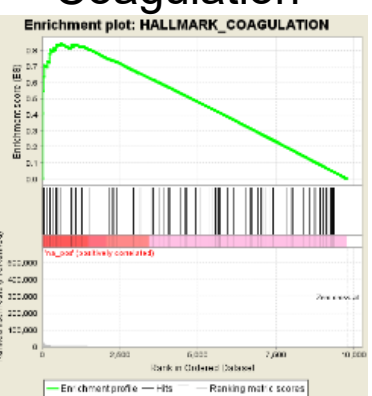

IL6/JAK/STAT3

HaLLMARK_LLE__ARK_STAT3_SIGNALING

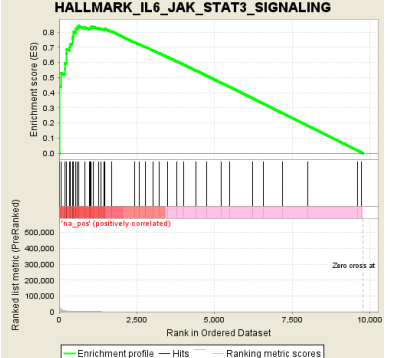

D

GTEx human whole blood

Heme metabolism

Complement

Estrogen response late

Reactive oxygen species

IFNa response

Apical junction

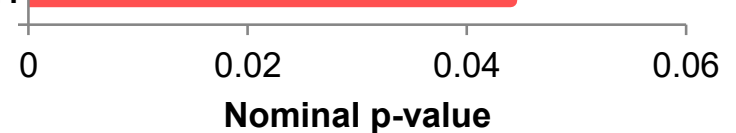

Nominal p-value

E human whole blood human whole blood

E (top 100 genes) (top 500 genes)

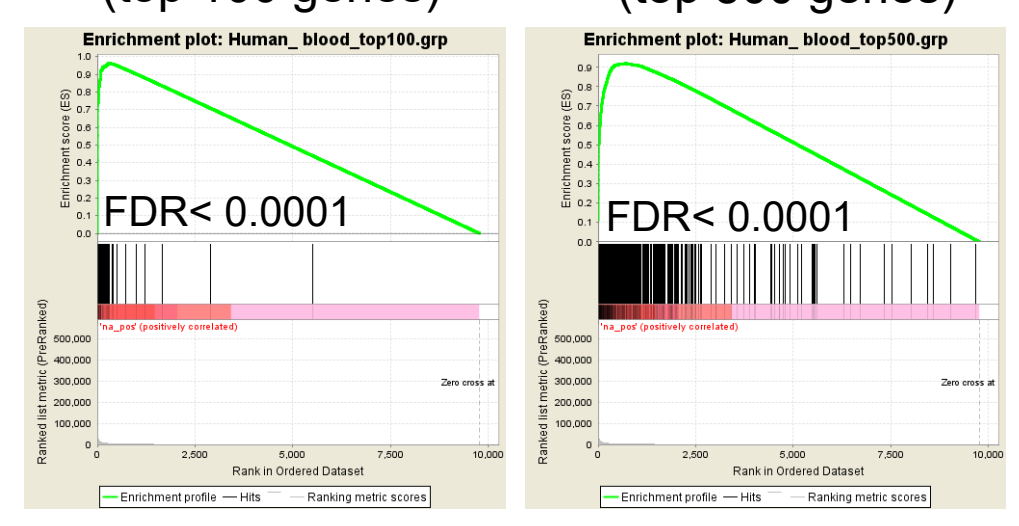




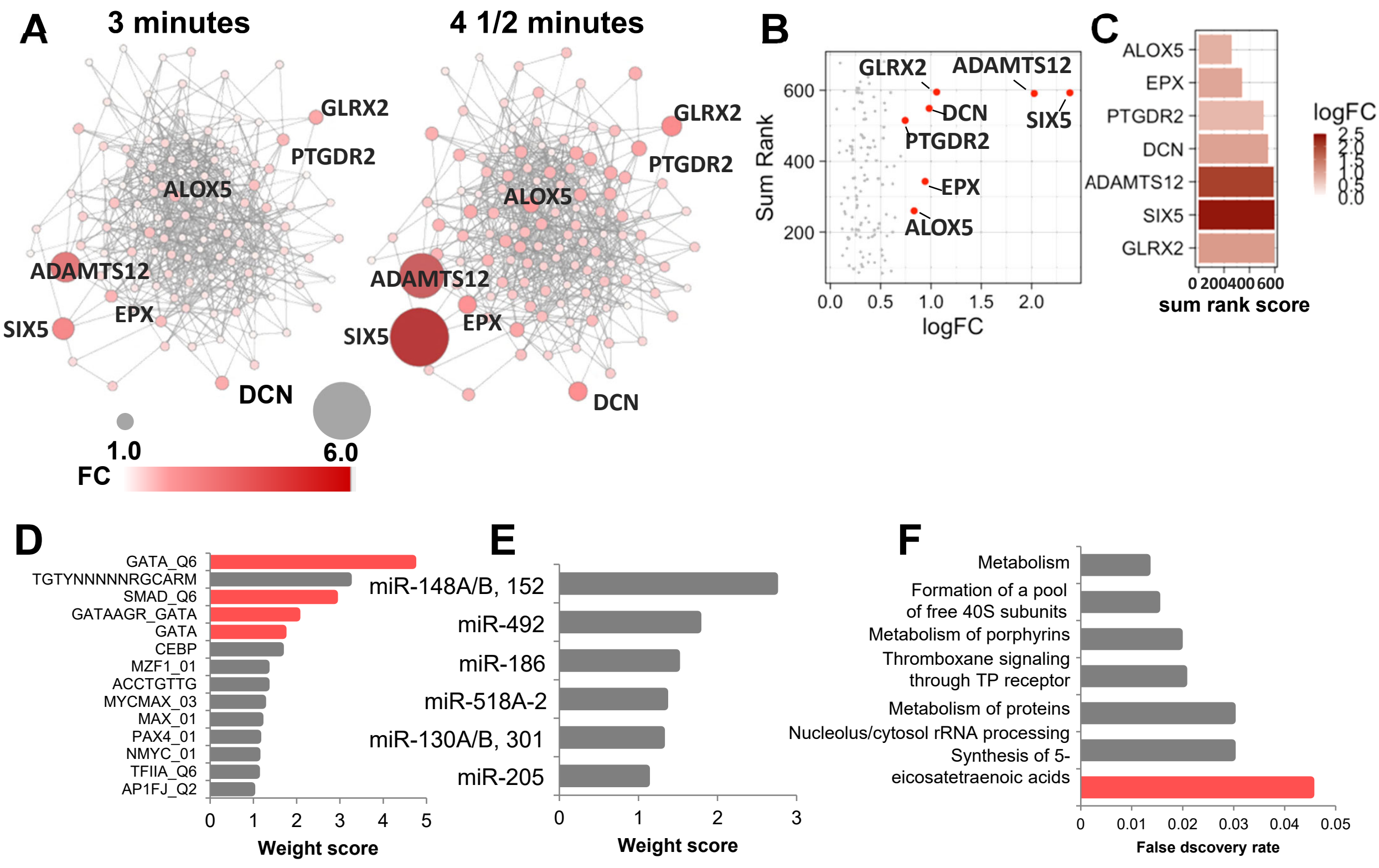



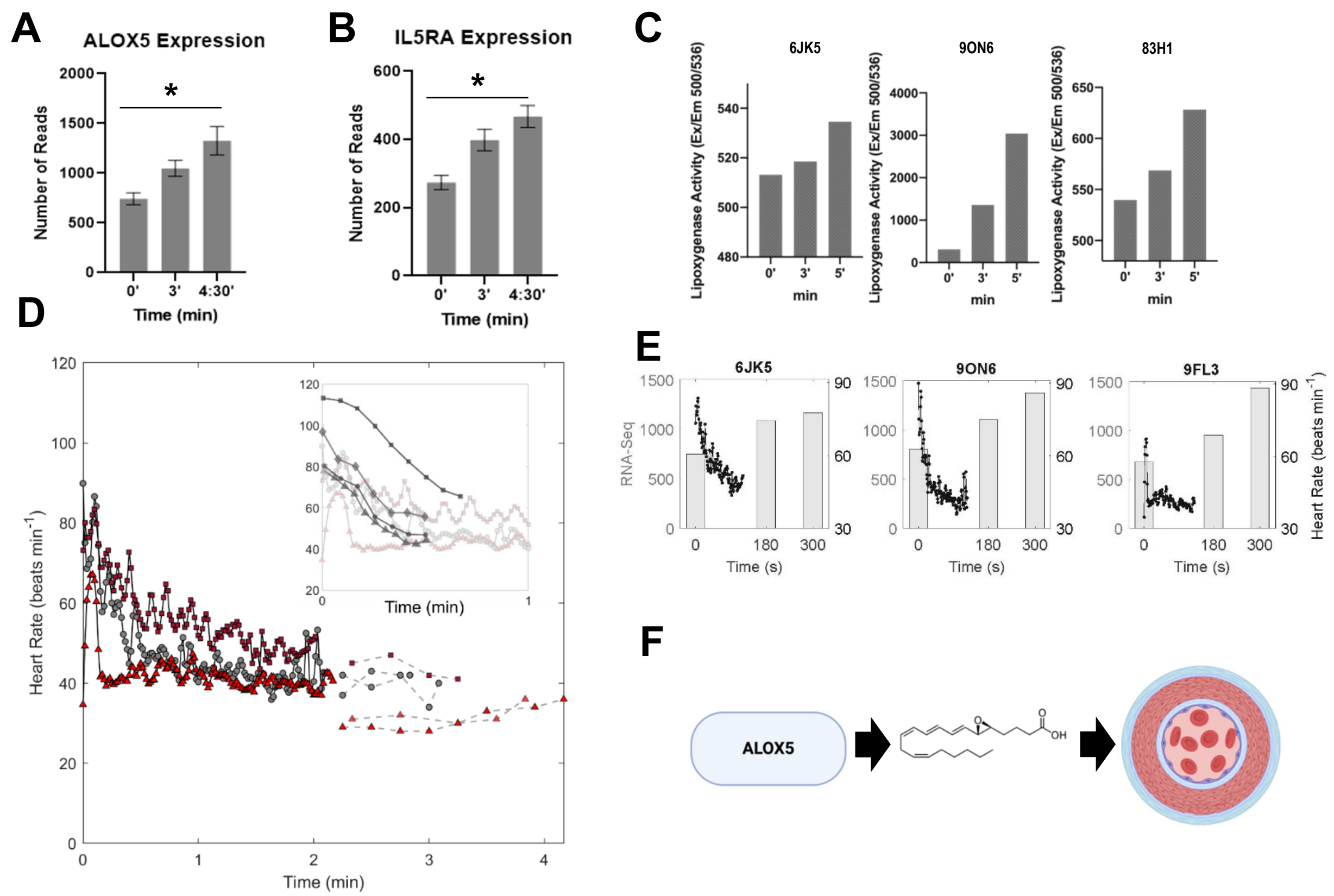

F
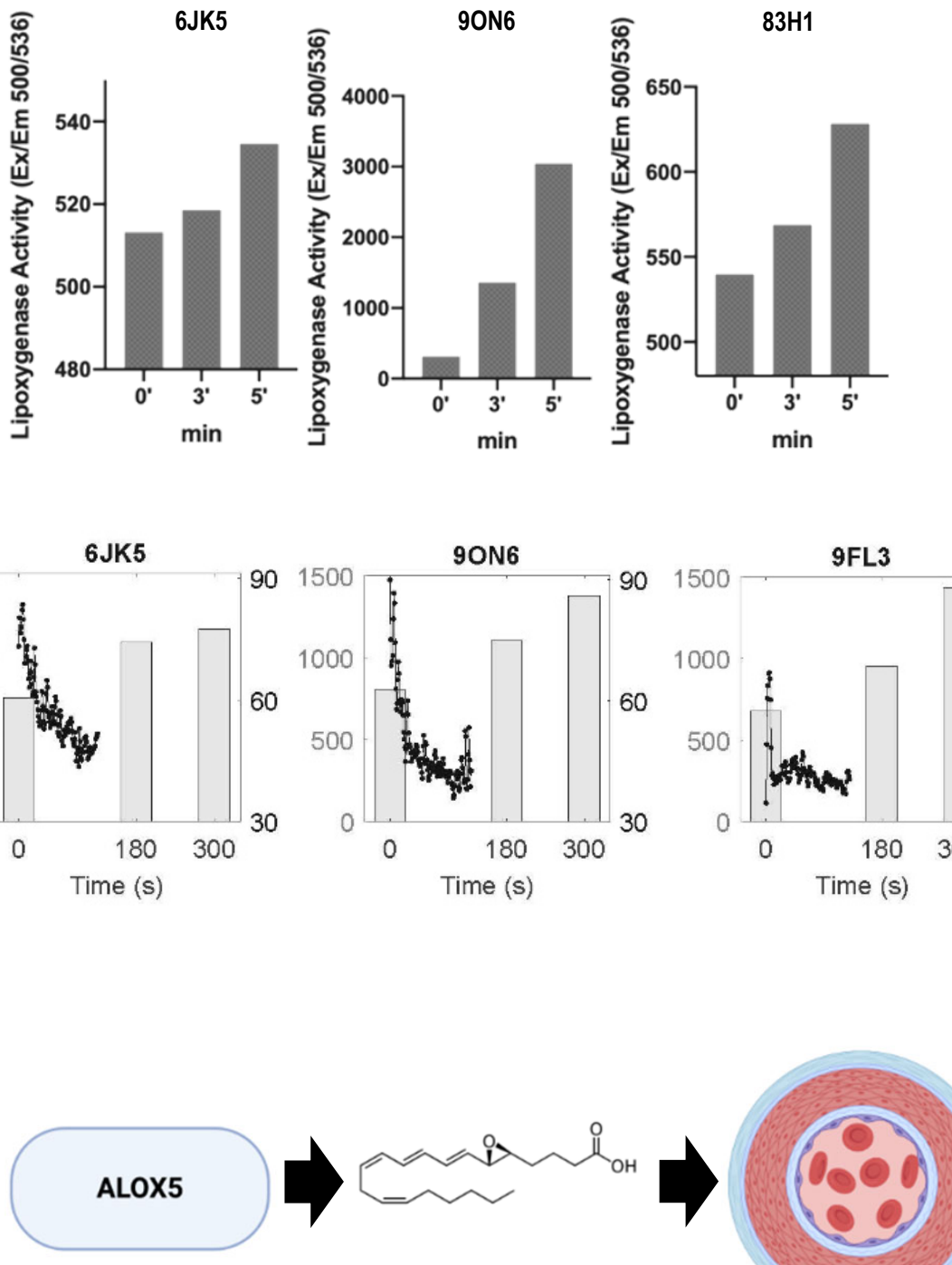


\begin{tabular}{|l|c|c|c|c|}
\hline Animal ID & $\begin{array}{c}\text { Age } \\
\text { (years) }\end{array}$ & $\begin{array}{c}\text { Body Mass } \\
(\mathbf{k g})\end{array}$ & $\begin{array}{c}\text { RNA- } \\
\text { Seq }\end{array}$ & $\begin{array}{c}\text { Lipoxygenase } \\
\text { assay }\end{array}$ \\
\hline 6 JK5 & 24 & 200.9 & $\mathrm{x}$ & $\mathrm{x}$ \\
\hline 9FL3 & 35 & 251.7 & $\mathrm{x}$ & \\
\hline $9 \mathrm{ON} 6$ & 21 & 192.8 & $\mathrm{x}$ & $\mathrm{x}$ \\
\hline $83 \mathrm{H} 1$ & 11 & 147.0 & & $\mathrm{x}$ \\
\hline Mean \pm S.D. & $22.8 \pm 9.9$ & $198.1 \pm 42.9$ & & \\
\hline
\end{tabular}

